\title{
Assessment of the menopausal symptoms of women by using the menopausal rating scale
}

\author{
Shweta Pradhan*, Anupama Dave
}

Department of Obstetrics and Gynecology, MGM Medical College and MY Hospital, Indore, Madhya Pradesh, India

Received: 12 February 2019

Accepted: 07 March 2019

\section{*Correspondence:}

Dr. Shweta Pradhan,

E-mail: shwetapradhan22@gmail.com

Copyright: (C) the author(s), publisher and licensee Medip Academy. This is an open-access article distributed under the terms of the Creative Commons Attribution Non-Commercial License, which permits unrestricted non-commercial use, distribution, and reproduction in any medium, provided the original work is properly cited.

\begin{abstract}
Background: Although menopause is a universal phenomenon, there is a considerable variation among women regarding the manifestation of menopausal signs and symptoms. Symptoms experienced with the menopausal transition and early post menopause are varied and span both physical and psychological domains. Therefore, a need is felt to evaluate menopausal symptoms on a pretested scale to provide a subjective and clinically reproducible picture of menopausal symptoms.

Methods: A descriptive cross-sectional study was conducted in MYH ,Indore Obstetrics and Gynecology Department, from July 2016 to December 2016.A pretested, semi structured, interview based, oral questionnaire was used to assess the menopausal symptoms and their severity in women of age group 35 to 65 years attending $\mathrm{MYH}$, Indore OPD, using MRS scale and to evaluate these symptoms in perimenopausal as compared to postmenopausal women.

Results: The results were evaluated for psychological (P), somatic (S), and urogenital (U) symptoms. A significantly higher percentage of perimenopausal women showed a $\mathrm{P}$ score of $\geq 7$; while a higher percentage of postmenopausal showed $\mathrm{S}$ score and $\mathrm{U}$ score $\geq 7 ; \mathrm{p} \leq(0.001)$. Working women seem to suffer more from psychological symptoms whereas nonworking women showed a greater incidence of somatic symptoms.

Conclusions: The present study revealed that proportion of menopausal symptoms was significantly high and there was variation of severity of menopausal symptoms with any of the socio demographic variables, menopausal status or duration of menopause.
\end{abstract}

Keywords: Menopause, Menopause rating scale, Somatic

\section{INTRODUCTION}

Although menopause is a universal phenomenon, there is a considerable variation among women regarding the manifestation of menopausal signs and symptoms. Symptoms experienced with the menopausal transition and early post menopause are varied and span both physical and psychological domains. ${ }^{1}$ Cultural differences may play an important role in the perception of the symptoms and affect the quality of life. ${ }^{2}$ The Menopause Rating Scale (MRS) was developed by Berlin
Centre for epidemiology and Health Research in response to the lack of standardized scales to measure the severity of menopause related symptoms and their impact on the health-related Quality of Life (HRQoL). FDA approval was granted in 2006, it is well accepted internationally and translated in 25 languages since then.

Menopause has not been well-investigated in our environment. Symptoms as narrated by menopausal women are usually vague and lack clinical correlation of their significance and severity. Such thinking derives 
support from the belief that the cultural background of our women contributes to their adjustment to menopausal changes. Menopause has been reported as one of the opportunities for women to visit health-care services. ${ }^{3}$ Therefore, a need is felt for a pretested scale to provide a subjective and clinically reproducible picture of menopausal symptoms and to find out the factors associated among women in Indore district. Menopausal rating scale (MRS), was chosen as a standardized instrument out of the other available due to its reliability, the short format encompassing all the associated symptoms and the simple scoring scheme. ${ }^{4}$ The scale is designed and standardized to act as a self-administered scale to assess the occurrence and severity of symptoms/complaints of menopausal women. According to MRS the symptoms/complaints can be identified into three dimensions: psychological $(\mathrm{P})$, somatic-vegetative (S), and urogenital (U). It consists of a list of 11 items (symptoms or complaints).Each of the 11 symptoms contained in the scale can get 0 (no complaints) or up to 4 scoring points (severe symptoms) depending on the severity of the complaints perceived by the women completing the scale (an appropriate box is to be ticked)

The study is aimed at determining the variations and severity of the menopausal symptoms with

- Age,

- Educated versus uneducated

- Working versus non-working women.

- Rural vs urban.

\section{METHODS}

A descriptive cross-sectional study was conducted in Maharaja Yeshwantrao Hospital, Indore Obstetrics and Gynecology Department, from July 2016 to December 2016 over 416 women. A pretested, semi structured, interview based, oral questionnaire was used.

\section{Inclusion criteria}

- Perimenopausal/ menopausal (natural/ surgical menopause)/ postmenopausal women were included in the study.

- Age: 35-65 years.

\section{Exclusion criteria}

- Women suffering from diabetes, hypertension and thyroid disorders

- Women suffering from any malignancies.

- Women with age $>65$ years.

- Patients suffering from arthritis

- Patients on exogenous sex hormones.

Age distribution:

Earlier studies have indicated mean age of menopause in the north-Indian population is $46.7+/-3.2$ years. $^{5}$
Based on this, authors divided our cohort into:

- Perimenopausal (35-45),

- Early menopause (46-51),

- Postmenopausal (52-65).

Tools of data collection: Questionnaires were divided into two sections:

Socio-demographic data of the participants, which included:

- Age in years, locality,

- Religion,

- Education,

- Occupation of the respondent.

Menopause Rating Scale A structured interview sheet that was developed, modified and translated and to collect the necessary data to be filled from menopausal women.

\section{RESULTS}

Three independent dimensions (psychological domain: which includes depressive mood, irritability, anxiety, physical and mental exhaustion; somato-vegetative domain including hot flushes, heart palpitations, sleep problems, joint and muscular pains; urogenital domain which includes sexual problems, dryness of vagina and bladder problems) have been identified out of the total list of 11 symptoms enlisted in MRS, i.e. psychological $(\mathrm{P})$, somato-vegetative $(\mathrm{S})$, and urogenital $(\mathrm{U})$ sub-scale. ${ }^{6}$

Authors can see in Table 1 that perimenopausal woman scored High on P-score while late menopausal women scored high on $\mathrm{S}$ and $\mathrm{U}$ score. The high $\mathrm{P}$ score in peri menopausal women may be due to rapid changes in estrogen level maladaptation to the recent onset of menopausal symptoms.

Table 1: Age wise distribution of symptoms.

\begin{tabular}{|l|l|l|l|}
\hline & $\begin{array}{l}\text { Peri } \\
\text { menopause } \\
\text { N=142 }\end{array}$ & $\begin{array}{l}\text { Early } \\
\text { menopause } \\
\text { N=128 }\end{array}$ & $\begin{array}{l}\text { Late } \\
\text { menopause } \\
\text { N=124 }\end{array}$ \\
\hline $\begin{array}{l}\text { P score }>7 \\
(n=136)\end{array}$ & 66 & 42 & 18 \\
\hline $\begin{array}{l}\text { S score }>7 \\
(n=107)\end{array}$ & 26 & 38 & 43 \\
\hline $\begin{array}{l}\text { U score }>4 \\
(n=68)\end{array}$ & 6 & 20 & 42 \\
\hline
\end{tabular}

The High S and U score in late menopausal woman may be attributed to significant decline in estrogen level with time. There was a significant difference among all age groups in each domain $(\mathrm{p} \leq 0.001)$. In present study authors considered educated as women having completed class 10th of schooling. Among patients, authors found, 64 women educated and Uneducated- 352. The data in 
Table 2 clearly shows that uneducated women reported a higher $\mathrm{P}$ and $\mathrm{U}$ score as compared to an almost similar $\mathrm{S}$ score between the two. ( $\mathrm{p}$ value $<0.001$ ).

Table 2: Education wise distribution of symptoms.

\begin{tabular}{|l|l|l|} 
& $\begin{array}{l}\text { Educated } \\
(\mathrm{n}=64)\end{array}$ & $\begin{array}{l}\text { Uneducated } \\
(\mathrm{n}=352)\end{array}$ \\
\hline P score $>7(n=136)$ & 54 & 82 \\
\hline S score $>7(n=107)$ & 53 & 52 \\
\hline U score $>$ 4 $(n=68)$ & 19 & 49 \\
\hline
\end{tabular}

This may in part be explained by better hygienic practices by educated women better knowledge of menopausal symptoms. Authors defined working women working out of their house for at least 8 hours, in our sample size, authors had Working women:158, while Non-working :242. In present study the $\mathrm{P}$ scores were reported higher by working women. Greater \% of working women due to overstress of work might suffer from more of psychological symptoms than the nonworking (Table 3 ).

Table 3: Employment wise distribution of symptoms.

\begin{tabular}{|l|l|c|}
\hline & $\begin{array}{l}\text { Working } \\
(\mathrm{n}=158)\end{array}$ & $\begin{array}{c}\text { Non-working } \\
(\mathrm{n}=242)\end{array}$ \\
\hline P score $>7(n=136)$ & 94 & 42 \\
\hline S score $>7(n=107)$ & 56 & 51 \\
\hline U score $>$ 4 $(n=68)$ & 28 & 40 \\
\hline
\end{tabular}

The S score was marginally higher in working women the $\mathrm{U}$ score was higher among non-working women. ( $p$ value $<0.01$ ). In present study as authors can see from Table 4 Rural women scored Higher in all Three domains Rural women were more of low socio-economic status so were more likely to encounter financial problems, issues of unemployment or underemployment, discrimination; there was the lack of education, poorer access to health services.

Table 4: Rural and urban distribution.

\begin{tabular}{|l|l|l|}
\hline & Rural & Urban \\
\hline P Score $>7$ & 52 & 40 \\
\hline S score $>7$ & 40 & 28 \\
\hline U score $>4$ & 12 & 7 \\
\hline
\end{tabular}

Whereas the women living in the urban area were having have more opportunities to be involved in social, cultural, or economic activities. In contrast, women in rural areas are more labile to a diminished self-esteem at the end of their child-bearing age.

\section{DISCUSSION}

The term "menopause" denotes the final cessation of menstruation, either as a normal part of aging or as the result of surgical removal of both ovaries. Some of menopausal symptoms experienced by these women can be severe enough to affect their normal daily activities.
The common climacteric symptoms experienced by them can be group into: vasomotor, physical, psychological or sexual complaints. ${ }^{7}$

The average age at menopause amongst the women under study was found to be $48.7 \pm 2.3$ years (46.4-51.0 years). Earlier studies have indicated mean age of menopause in the north-Indian population to be 46.7 years. ${ }^{5}$ This agree with study conducted by (Dhillon et al,2006 and palacios et al who reported that the mean age at menopause was $51.14 \pm 2.11$ years, and varies with (Elsayed $E$ and Shokery E. who mentioned that the study conducted in zagazig about menopausal symptoms and the quality of life among pre/post-menopausal women from rural area in Zagazig city, the mean age of women was 54.0 \pm 7.9 years. ${ }^{8,9}$ Present study showed, the highest percent $(60 \%)$ as a house wife ,this is similar with (Huszla, et al who mentioned that the most of women about (56,5\%) employed, in their study carried in Poland about effects of socio- demographic, personality and medical factors on quality of life of post-menopausal women. ${ }^{10}$ The present study revealed that the most prevalent symptoms in the MRS score: physical and mental exhaustion, joint and muscle aches was severe among women about $(37.2 \%)$, this is in contrast with Yakout et al who mentioned that the majority $(85.0 \%)$ of women have severe degree of hot flushes in their study about Menopausal Symptoms and Quality of Life among Saudi Women in Riyadh and Taif. ${ }^{8}$

The present study shows that, less than one third (28.4\%) of women have moderate sexual problems and this disagree with Yakout et al, who mentioned that more than one- half $(62.5 \%)$ of women have severe sexual problems in their study about Menopausal Symptoms and Quality of Life among Saudi Women in Riyadh and Taif. Also, Reda R Ali et al, in their study found prevalence of sexual symptoms to be $38 \%$. $^{1,11}$ Authors observed that perimenopausal woman scored High on P-score while late menopausal women scored high on $\mathrm{S}$ and $\mathrm{U}$ score. These findings are similar with a study done by Kakkar et al. ${ }^{12}$

\section{CONCLUSION}

The present study revealed that proportion of menopausal symptoms was significantly high and there was variation of severity of menopausal symptoms with any of the socio demographic variables, menopausal status or duration of menopause. Further, it may be highlighted that patient related information should be noted by the physician, and suitable approach should be adopted accordingly, for achieving better therapy outcomes. For example, as observed in this study and also suggested in literature, the newer stress of modernization and work, may result in a greater frequency of psychological symptoms. This was observed more specifically in the younger patient group (perimenopausal) and also in the working women. So, it may be concluded that an interaction with a counsellor and suitable advice about 
the non-therapeutic options can help alleviate the problems of this patient group. The final outcome of the study emphasizes the importance of counselling in improving the overall state of the menopausal women.

Funding: No funding sources

Conflict of interest: None declared

Ethical approval: The study was approved by the Institutional Ethics Committee

\section{REFERENCES}

1. Ali R. Impact of menopausal symptoms on quality of life among women's in Qena City; IOSR J Nursing Health Sci. 2015;4(2):49-59.

2. Budakoğlu Iİ, Özcan C, Eroğlu D, Yanik F. Quality of life and postmenopausal symptoms among women in a rural district of the capital city of Turkey. Gynecol Endocrinol. 2007;23(7):404-9.

3. Guthrie JR, Dennerstein L, Taffe JR, Lehert P, Burger HG. Hot flushes during the menopause transition: a longitudinal study in Australianborn women. Menopause. 2005;12(4):460-7.

4. Hauser GA, Huber IC, Keller PJ, Lauritzen C, Schneider HP. Evaluation der klinischen beschwerden (menopause rating scale). Zentralbl Gynakol. 1994;116(1):16-23.

5. Kriplani A, Banerjee K. An overview of age of onset of menopause in northern India. Maturitas. 2005;52(3-4):199-204.

6. Heinemann K, Assmann A, Möhner S, Schneider HP, Heinemann LA. Reliabilität der Menopause-Rating-Skala (MRS). Zentralblatt für Gynäkologie. 2002;124(03):161-3.
7. Gharaibeh M, Al-Obeisat S, Hattab J. Severity of menopausal symptoms of Jordanian women. Climacteric. 2010 Aug 1;13(4):385-94.

8. Dhillon HK, Singh HJ, Shuib R, Hamid AM, Mahmood NM. Prevalence of menopausal symptoms in women in Kelantan, Malaysia. Maturitas. 2006;54(3):213-21.

9. Elsabagh EE, Abd Allah ES. Menopausal symptoms and the quality of life among pre/post-menopausal women from rural area in Zagazig city. Life Sci J. 2012;9(2):283-91.

10. Wieder-Huszla S, Szkup M, Jurczak A, Samochowiec A, Samochowiec J, Stanisławska M, Rotter I, Karakiewicz B, Grochans E. Effects of socio-demographic, personality and medical factors on quality of life of postmenopausal women. International journal of environmental research and public health. 2014;11(7):6692708.

11. Yakout SM, Kamal SM, Moawed S. Menopausal symptoms and quality of life among Saudi women in Riyadh and Taif. J Am Sci. 2011;7(5):776-83.

12. Kakkar V, Kaur D, Chopra K, Kaur A, Kaur IP. Assessment of the variation in menopausal symptoms with age, education and working/nonworking status in north-Indian sub population using menopause rating scale (MRS). Maturitas. 2007;57(3):306-14.

Cite this article as: Pradhan S, Dave A. Assessment of the menopausal symptoms of women by using the menopausal rating scale. Int J Reprod Contracept Obstet Gynecol 2019;8:1436-9. 